\title{
Observations of Ice Drift from a Manned Drifting Station in the Gulf of St. Lawrence
}

\author{
D. Farmer ${ }^{1,3}$, O. M. Johannessen ${ }^{1}$, J. E. Keys' ${ }^{2}$, E. R. Pounder', \\ AND H. SERSON ${ }^{2}$
}

\begin{abstract}
The positioning of a drifting ice floe was recorded every 10 minutes during a six-day period by means of a Decca navigational system and by direct wind observations on the floe. The observations showed that the ice floe took part in the tidal regime. Maximum correlation between wind and residual ice drift speeds (tidal effect eliminated) was achieved in less thian 2 hours.
\end{abstract}

\section{INTRODdCTION}

A recent paper [Ingram et al., 1969] described the early stages of a continuing study of ice drift in the Gulf of St. Lawrence that was organized by the Marine Sciences Centre, McGill University. The first experiment consisted of tracking a buoy, which had been equipped with a radio beacon and placed on an ice floe, with ice reconnaissance aircraft. The practicability of using such a buoy in ice studies was established, but it became clear that frequent positioning of a floe was necessary owing to the major influence of tidal current and to the significant accelerations of the floe.

An attempt to observe the relationship at frequent time intervals between wind and ice drift vectors was made in the winter of 1968 [Johannessen et al., 1968]. We established a drifting station (Figure 1) on an ice floe off the Gaspé Coast in the Gulf of St. Lawrence on February 12, with the assistance of the Canadian Coast Guard icebreaker d'Iberville, which used a pneumatic liferaft manned by three persons. The floe was about $5 \mathrm{~km}$ long by $3 \mathrm{~km}$ across. The manned drifting station, hereafter referred to as MDS, drifted eastward under the influence of severe weather conditions. High winds and low temperatures, which

\footnotetext{
1 Marine Sciences Centre, McGill University, Montreal, Canada.

2 Defence Research Establishment Ottawa, Defence Research Board, Ottawa, Canada.

${ }^{8}$ Now at Institute of Oceanography, University of British Columbia, Vancouver, Canada.
}

Copyright (c) 1970 by the American Geophysical Union. affected the power supply used to drive the navigational equipment, forced the evacuation of the MDS after 6 days of drift.

During the winter of 1969 [Johannessen et al., 1969] a small ship (sealer) was used as a platform for drift studies. In addition to routine measurements of position, wind velocity, and current, oceanographic stations were taken and special investigations were made of wind and water stress. Wind stress was studied by the eddy flux method through use of an ultrasonic anemometer [Smith et al., 1969], and water stress just below the ice was studied by the profile method. Interactions between adjacent ice floes can give rise to internal stress or ice pressure, which can be an important factor in ice drift and in the ease of ship navigation through an ice field. To observe the relative motion of the floes, we placed large radar reflectors on several of the floes and tracked them by the ship's radar to distances up to $\mathbf{5 . 5}$ nautical miles from the ship. The 1969 observations are being analyzed in detail.

Simultaneously with the field program, a theoretical study of the ice-water circulation is under way, and our ultimate aim is to formulate a realistic numerical model of this circulation in the Gulf that can be used as a tool in ice forecasting. The present brief report gives some of the conclusions from the 1968 experiment.

\section{Observations}

The MDS was equipped with a Decca navigational system and a paper tape digital printer. Output from the Decca system was in two 


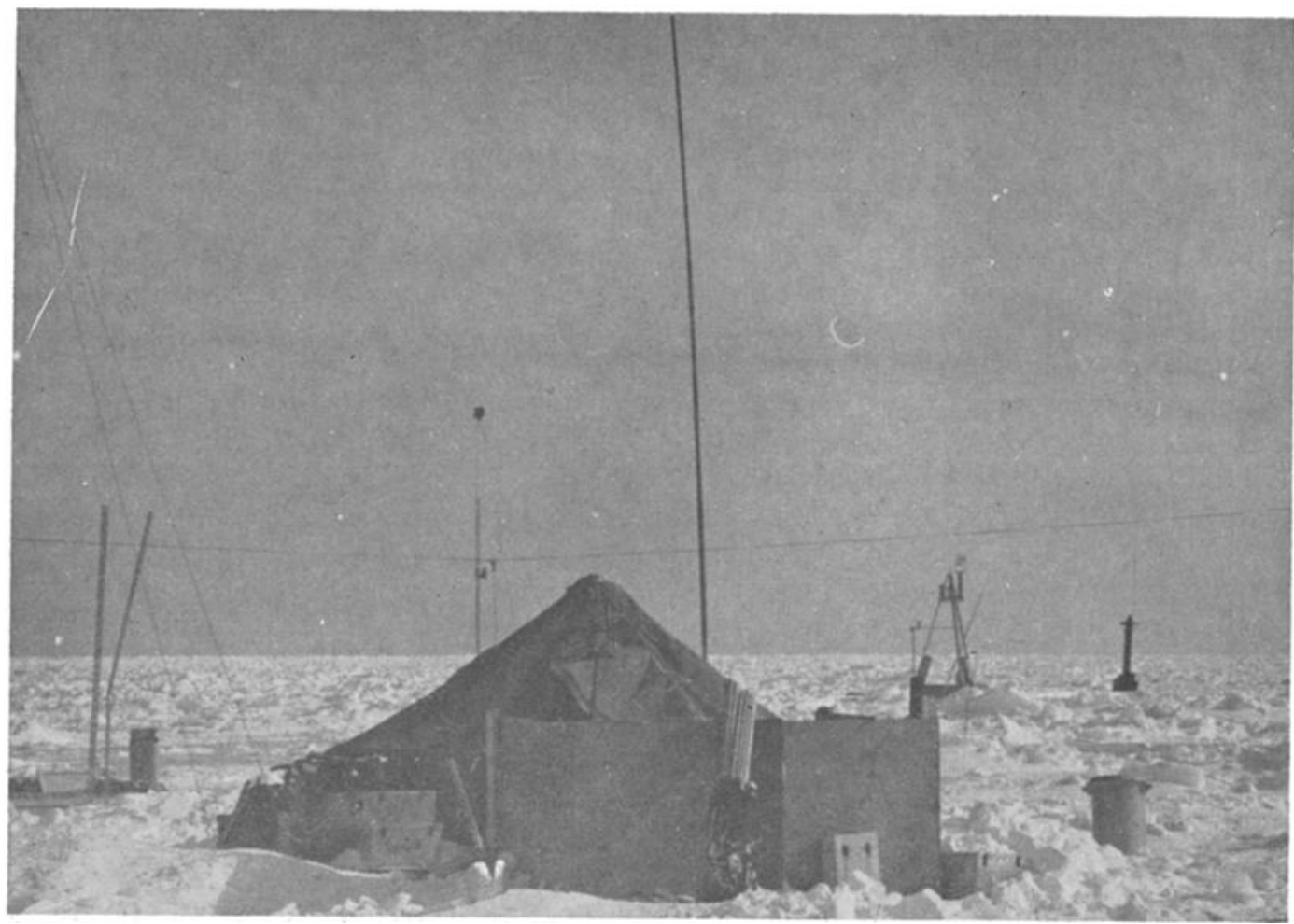

Fig. 1. The camp on the drifting ice floe.

forms, the output provided by the paper tape printer every 2 minutes and output recorded by hand every 15 minutes. The absolute accuracy of the Decca system where the MDS drifted is \pm 200 meters with a relative accuracy of \pm 20 meters, or better.

The Decca coordinates were converted into latitude and longitude for readings at 10-minute intervals, and Aitken-Lagrange interpolation based on the manually recorded observations was used when the paper tape recorder malfunctioned. Figure 2 shows the drift of the ice floe with its positions given at time intervals of 3 hours. For each time step of 10 minutes, velocities were estimated by fitting Gram orthogonal polynomials to 3 -hour sections (using the least-squares criterion) and by analytically differentiating at the midpoint. This process smoothed out short-period random fluctuations. Figure 3 shows the resulting north and east components of the velocity, plotted for every 10 minutés.

The ice concentration in the area where the MDS drifted was $70-90 \%$ and young thick winter ice was predominant. The topography of the particular floe where the MDS was located was very rough. Thickness measurement could vary from 0.5 to 2.8 meters over a horizontal separation of 10 to 15 meters. Repeated ice thickness measurements within an area of $100 \mathrm{~m}^{2}$ indicated a growth of $20 \mathrm{~cm}$ in 5 days.

Tidal analysis. In the Gulf of St. Lawrence tides are propagated principally through the Cabot Strait, with the semidiurnal constituent dominant [Farquharson, 1962]. As seen from Figures 2 and 3 , the ice floe was greatly affected by tidal motion, but, in order to study the response of the ice drift to changing wind stress, it was necessary to eliminate the tidal influence on the floe. This task is a difficult one because the observation period is short, the wind-driven velocity and tidal components are of comparable size, and the floe drifted rapidly eastward through a changing tidal regime.

Attempts to eliminate the semidiurnal and diurnal component were made by using a method (given by Fjeldstad [1964]) that is particularly appropriate for short-period data. 


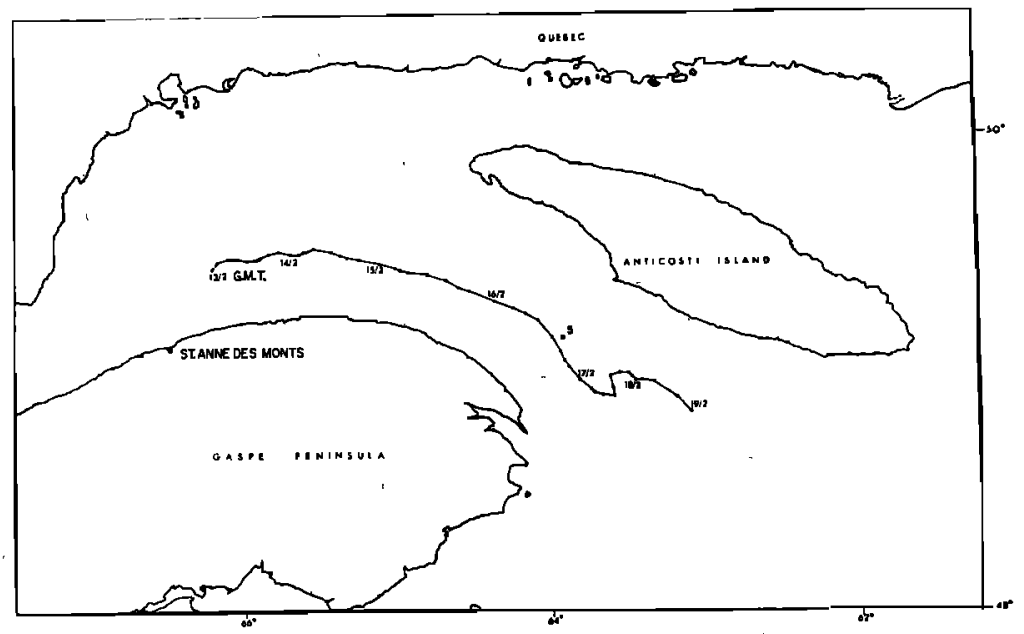

Fig. 2. The observed drift of the ice floe. Positions are plotted at 3-hour intervals, with the position at the beginning of each day dated.

If one assumes that the total observed drift in northerly and easterly directions respectively can be described by second-order polynomials and a harmonic term, the noncyclic part can be removed by taking 6 -hour differences twice for the semidiurnal component, and 12-hour differences twice for the diurnal component, using 37- and 74-hour observation series respectively. The wind-driven motion having (hopefully) been eliminated in this way, the remaining drift was used for tidal ellipse calculations. These calculations were iterated every 10 minutes, intervals corresponding to the spacing of the data. The variation of the tidal axes is shown in Figure 4. Negative values of the minor axis indicate clockwise rotation. The variation of the axes must be partly a consequence of analyzing data from a changing tidal regime, but it is also a result of the strong meteorological effects, which can be represented only approximately by a second-degree polynomial.

If one assumes that the ice floe can freely take part in the tidal motion, the result of the harmonic analysis will give information on the

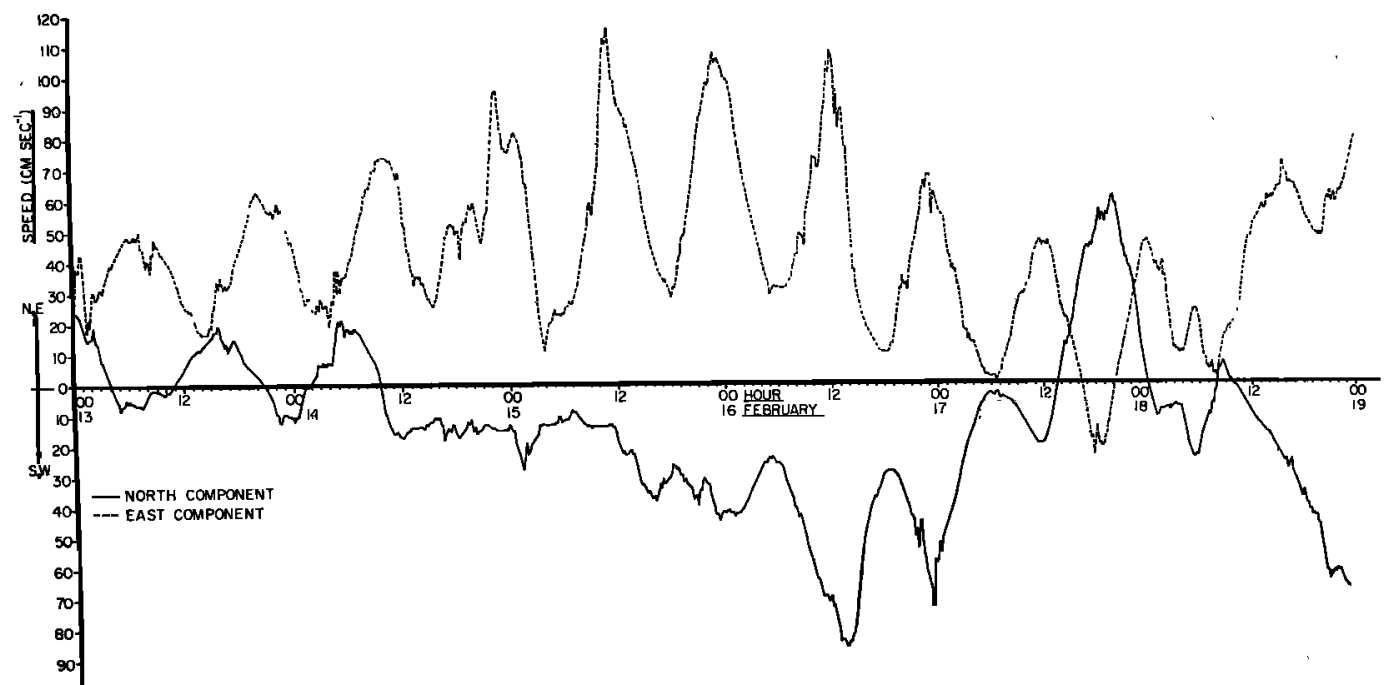

Fig. 3. North and east components of the velocity of the floes, February 13-19, 1968 


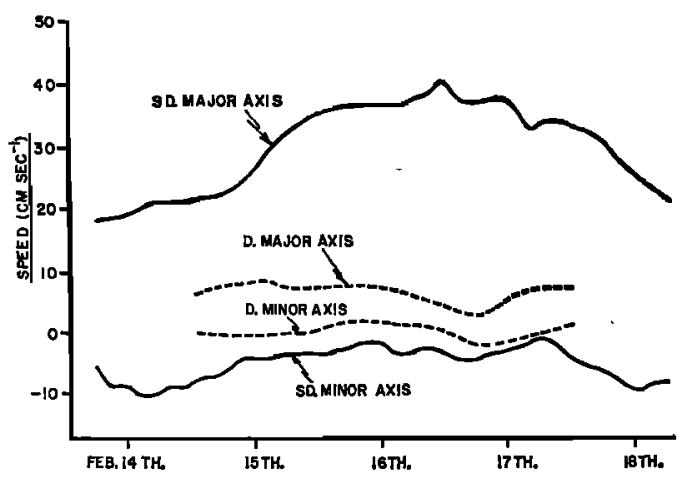

Fig. 4. Ellipse parameters of semidiurnal (SD) and diurnal (D) tidal constituente.

tidal current in the area. No surface measurements are available, however. Farquharson [1966] gave some results from tidal analysis in the Gaspé Passage at a depth of 13 meters. He reported a mean value of the semidiurnal major axis of 0.34 knot at station 5 (Figure 2), as compared with a value of 0.70 knot found in this analysis. This agreement is reasonable if the depth difference and the present short series of observations are taken into consideration.

By applying the result from the harmonic analysis the tidal component was eliminated. The residual ice drift and the wind observation are shown in Figure 5. Tidal components at the two ends of the drift run were calculated by use of the first and the last tidal ellipses. Some of the tidal influences are still present, and power spectrum analysis after removal of tidal influence yields a peak at the semidiurnal frequency approximately one-fifth that at the same frequency in the spectrum for the original data. The wind and ice speed in Figure 5 are plotted in the ratio $1: 50$ to test an empirical rule of Nansen that the ice should drift with $2 \%$ of the wind speed. However, as Figure 5 clearly demonstrates, this rule cannot be used directly to predict ice movement in the Gaspé Passage. It is believed that the semipermanent Gaspé current causes very high drift rates, in addition to the wind effect.

Transient response. The strongly transient characteristics of the drift pattern provide an opportunity for determining the response of the ice to a change in the wind stress. Wind velocities were compared throughout the drift period with drift velocities for different lag times in 10-minute steps. Drift velocities after deduction of the tidal component were used. Both wind and drift velocities were normalized before comparison by setting the means of each series equal to zero and the standard deviations equal to unity.

The correlation was sought for successive lag steps by means of the method given by Blackman and Tukey [1958]. Maximum correlation is achieved in less than 2 hours (Figure 6), and the rapid decrease after this point must be attributed to the continual variation of the wind.

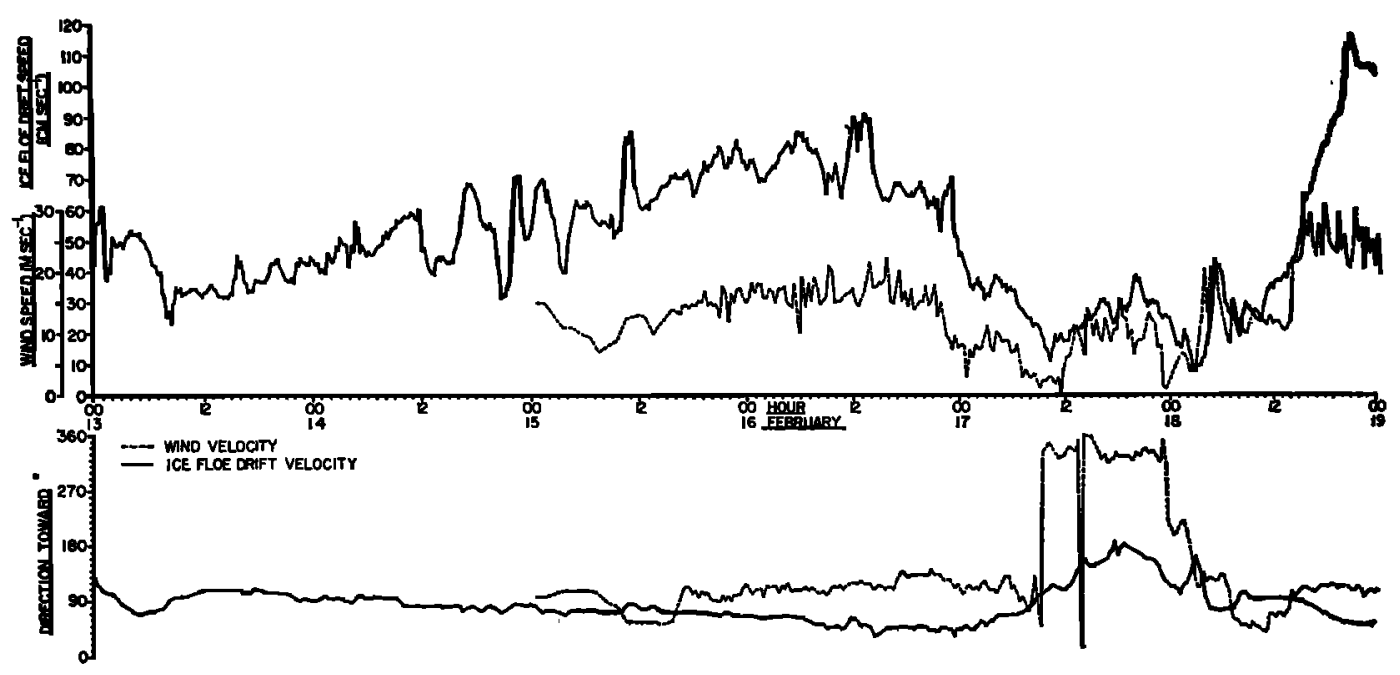

Fig. 5. Residual floe velocity and wind velocity. 


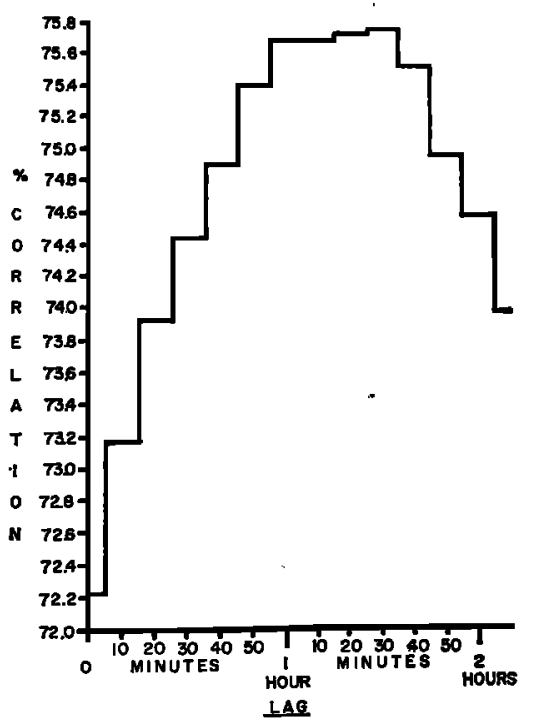

Fig. 6. Cross correlation of normalized drift velocity lagging normalized wind velocity.

\section{Conclusions}

Observations from a manned drifting station in the Gaspé Passage in the Gulf of St. Lawrence showed that the ice floe took part in the tidal regime. Harmonic analysis of the movement of the floe gave average values of $0.6 \mathrm{knot}$ for the major axis of the semidiurnal component and 0.1 knot for the minor axis, with a clockwise rotation of the motion. The diurnal component is about one-fifth the semidiurnal component, which agrees with the work of Farquharson [1962].

Cross correlation between the residual motion of the floe and the wind speed showed that maximum correlation was established in less than 2 hours.

Acknovoledgments. Two of the authors, J. Keys and H. Serson, were on board the MDS. Grateful thanks go to the third man on board, W. Seifert, Polar Continental Shelf Project (PCSP), D. Lindsay, PCSP, who acted as the shore- based radio operator, and Dr. F. Rootes, PCSP, who provided helicopter and other logistic support. Thanks go also to Marine Operations, Department of Transport, for icebreaker support and to W. Markham, Ice Forecasting Centre, De partment of Transport, for advice and prediction services.

This work was supported by the Defence Research Board of Canada, the Polar Continental Shelf Project, Department of Energy, Mines and Resources, and the National Research Council of Canada under grant T-2645.

\section{REFERENCES}

Blackman, R. B., and J. W. Tukey, The Measurement of Power Spectra from the Poinl of View of Communications Engineering, Dover, New York, 1958.

Farquharson, W. I., Tides, tidal streams and currents in the Gulf of St. Lawrence, Dep. Mines Tech. Surv., Ottawa, 1962.

Farquharson, W. I., St. Lawrence estuary current surveys, Bedford Inst. Oceanog. Rep. 66-6, 84 pp., 1966.

Fjeldstad, J. E., Internal waves of tidal origin, 1, Theory and analysis of observations, Geophys. Publ. Oslo, 25(5), 1-73, 1964.

Ingram, R. G., O. M. Johannessen, and E. R. Pounder, Pilot study of ice drift in the Gulf of St. Lawrence, J. Geophys. Res., 74, 5453-5457, 1969.

Johannessen, O. M., E. R. Pounder, H. Serson, J. Keys, D. Lindsay, W. Siefert, and E. Banke, Preliminary report on the 'Ice drift study' in the Gulf of St. Lawrence, winter 1968, Mar. Sci. Centre, MS Rep. S-13, McGill University, Montreal, 1968.

Johannessen, O. M., S. Smith, E. R. Pounder, J. Keys, H. Serson, E. Banke, and D. Finlayson, Preliminary report from the McGill ice drift study in the Gulf of St. Lawrence 1969, Mar. Sci. Centre Manuscript Rep. 11, McGill University, Montreal, 1969.

Smith, S. D., E. Banke, O. M. Johannessen, Some measurement of Reynolds stress over ice in the Gulf of St. Lawrence, A preliminary note, Bedford Institute of Oceanography, internal note, January 26, 1969.

(Received February 16, 1970.) 